The arrival time of the first Motorcycle EMT to the scene is within 1-10 minutes, was, previously, with the regular ambulance service, the arrival time was between 5-60 minutes. Also, the first EMT on the scene now is able to determine if the ambulance really is necessary, avoiding spending valuable resources on patients who don't require ambulance services.

Conclusion: While the development of this project has taken considerable time and discussion (including safety and political issues), its implementation has allowed the Local Fire Department to increase the reach of their medical team and also decrease the cost of their operations.

Keywords: emergency medical technicians; emergency medical services; Mexico; motorcycles; response; time

Prebosp Disast Med 2005;20(2):s99-s100

Epidemiology of Burns in Edo State, Nigeria: The Need for Appropriate Documentation and Policy Interventions

E. Okparavero

Ghana, Africa

The complications and sequelae associated with burn injuries are one of the most devastating forms of traumatically induced injuries. The objective of this study was to define the vacuum created by the lack of appropriate and complete data during disasters. This is essential for establishing the importance trauma as a public health problem, and therefore, requires acquiring accurate data concerning its incidence and outcomes. Such documentation is essential in order to move towards shaping policies that will forestall the recurrence of certain incidents and the prevent future disasters.

The ability to document that the incidence of traumainduced injuries is reaching epidemic proportions in developing countries like Nigeria depends heavily on the use of healthcare records obtained primarily from records of hospital admissions and emergency department visits. Currently, these data only are of limited value since many of them are incomplete, and thus provide an imperfect picture of the overall situation. This has a serious effect, since without this documentation, appropriate personnel, facilities, and money will not be made available to deal with emergency or disaster situations.

Keywords: data; documentation; incidence; Nigeria; records; resources; trauma-induced injuries

Prebosp Disast Med 2005;20(2):s100
Playing Nicely in the Sandbox: The Monumental Task of Multi-Agency Coordination in Preparing for the United States Presidential Inauguration in the Nation's Capital

C. Catlett

The George Washington University Center for Emergency Preparedness, Washington, DC USA

Washington, DC has its share of challenges when it comes to the complexities of federal and local cooperation during major emergencies and events. Due to its high-profile nature, preparations began in the fall of 2004 for the 20 January 2005 inauguration of President Bush, the first inaugural event since 11 September 2001. In addition to conventional disasters (fires, transportation crashes, etc.), disruptive demonstrations and terrorist attacks are contingencies for which plans were made. The nation's capital launched a massive, multi-jurisdictional, multi-agency effort to coordinate its preparedness and response for the weeklong activities. A veritable alphabet soup of federal, state, and local response agencies met regularly to gain an understanding of respective functions and hash out issues of resource sharing, command and control, coordination, communications, security, and transportation. The presentation will focus on the coordination of medical response between local agencies, such as hospitals, the DC Department of Health, and DC Fire and Emergency Medical Services, and federal agencies/assets such as the United States Armed Forces and the National Disaster Medical System. A summary of the medical care provided during the week-long event will be presented.

Keywords: coordination; multi-agency; preparedness; response; terrorism; Washington, DC

Prebosp Disast Med 2005;20(2):s100

Need for a Nationwide Coordination Model for Disasters Involving Large Numbers of Burns and Current Status of Turkish Burn Care Facilities

M. Haberal; O. Basaran; A. Kut; E. Sakallioglu; G. Moray Baskent University Faculty of Medicine, Turkey

Burn injuries are one of the most common types of injuries during or following a disaster. In regards to natural disasters, Turkey is considered one of the most threatening places on earth. Since the beginning of the 20th Century, there have been 90 earthquakes, leading to a combined total of 82,359 deaths and 567,297 damaged buildings in Turkey. Between 1988 and 2001, there were 443,119 firerelated events, which led to 2,569 deaths, resulting from burns alone. According to data from March 2003, there are 218 beds in 23 specialized burn units nationwide and an additional 76 burn care beds reserved in hospitals that do not contain burn units $(0.44 / 100,000$ beds). Although burn units and hospitals with dedicated burn beds are widely distributed across the country, the cooperation between these burn units and hospitals and the healthcare system in Turkey needs to be coordinated, especially in disaster situations. 
This study describes the current status of burn care in Turkey and underlines the need for a nationwide coordination model, especially useful in disaster situations. The essential elements of this study describe basic preparedness standards of the burn units in Turkey and describe the stepwise triage process from the disaster area.

Keywords: burns; coordination; disaster; facilitics; nationwide; preparedness; plan; Turkey

Prebosp Disast Med 2005;20(2):s100-s101

\section{Basic Life Support (BLS) and Automated External Defibrillator (AED) Course for Personnel in Kobe University Hospital}

T. Kawashima; N. Ishii; H. Nakao; Y. Maeda; M. Terukina; N. Okada; A. Takabasbi; S. Munn; Y. Okashiro; T. Yoshida Kobe University Graduate School of Medicine, Japan

Introduction: In July 2004, the public access defibrillation (PAD) system with automated external defibrillator (AED) was permitted in Japan.

Objective: To evaluate the effects of the basic life support (BLS) and AED courses provided to all Kobe University Hospital personnel.

Methods: The course has been conducted twice a month since June 2004, with a capacity of 18 learners (six teams of three). The changes between pre-test and post-test scores were examined for the 29 medical residents, 37 staff doctors, and 88 nurses. A lecture about BLS and AED was presented for all personnel in November. The effects of the course were examined by comparing the results obtained from two groups: (1) Group A, consisting of eight staff doctors and 42 nurses who took the course; and (2) Group $\mathrm{B}$, which included 55 staff doctors and 116 nurses who did not take the course.

Results: The medical residents obtained an average score of $11.5 \pm 0.5$ on the pre-test, and $17.6 \pm 2.1$ on the post-test. The staff doctors obtained an average score of $8.6 \pm 2.9$ on the pre-test, and $17.3 \pm 1.7$ on the post-test. The nurses obtained an average score of $8.4 \pm 3.2$ on the pre-test, and $16.3 \pm 2.1$ on the post-test. Although the study effect was confirmed by the post-test, it did not result in perfect scores. Although the staff doctors in Group B $(n=55)$ obtained an average score of $9.2 \pm 3.4$, those in Group A (n $=8$ ) obtained an average score of $15.9 \pm 4.6$. Although the nurses in Group B ( $n=116)$ obtained an average score of $6.9 \pm 3.6$, those in Group A $(n=42)$ obtained an average score of $13.6 \pm 4.0$. The scores of the course participants were higher than were those of the non-participants, but it was less than the post-test scores at the end of the course. Conclusions: The positive effect of the course was confirmed. In order to maintain the skills of the staff, additional short courses are required.

Keywords: automated external defibrillation (AED); basic life support (BLS); doctors; education; nurses; training Prehosp Disast Med 2005;20(2):s101
Planning and Preparedness for Mass-Gathering Events-EURO 2004

$M$. Soares-Oliveira; I. Santos; N. Pereira; V. Ferreira

Instituto Nacional de Emergência Médica (INEM), Portugal

Introduction: Few guidelines or benchmarks have been reported in the medical literature for the process of planning and preparedness for mass-gathering events by a national emergency medical services (EMS) system.

Objective: To describe the participation of the national EMS system in the planning and preparedness for the European Football Championship (EURO 2004) in Portugal.

Methods: The participation of the national EMS system in Portugal in the planning and preparedness for EURO 2004 was observed, and then the observations were synthesized in a descriptive report.

Results: The national EMS system in Portugal participated in planning and preparedness activities for EURO 2004 in three phases, which covered a diverse array of issues. In Phase 1, during stadium construction, activities included: (1) collaboration on the production or revision of the hospital, airport, and stadium emergency plans; (2) communication with embassies; (3) communication with public safety services (e.g., fire brigade and police authorities); and (4) communication with health services (e.g., public health and forensic medicine agencies). In Phase 2, after the stadiums were constructed, activities included: (1) stadium site visits to determine the space and location for emergency medical teams; (2) study of stadium access routes (including highways, railways, and airports); (3) emergency medical team training via workshops, exercises, and simulations; (4) emergency medical team testing during preparatory games; and (5) recruitment of translators. In Phase 3, during the games, activities included: (1) creation of a 24-hour Crisis Management Center; (2) reinforcement of emergency medical services at the airport, diversion zones, and main traffic routes surrounding the stadiums; (3) allocation of an emergency medical team to accompany the referees and the football teams; and (4) creation of an emergency medical team for each stadium, consisting of approximately 100 emergency care workers per game.

Conclusions: The participation of a national EMS system may facilitate the planning and preparedness for massgathering events. This experience may contribute to the establishment of guidelines and benchmarks for EMS system planning and preparedness for mass-gathering events. Keywords: communication; emergency medical services (EMS); mass-gathering events; Portugal; planning; preparedness Prebosp Disast Med 2005;20(2):s101 